\title{
Antecedentes e Consequências da Participação de Advisor em Fusões e Aquisições
}

\author{
Motivations and Consequences of Advisor Participation in Mergers and Acquisitions
}

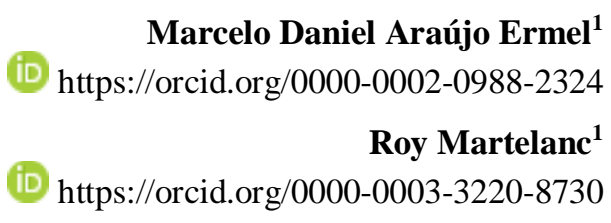

Universidade de São Paulo, Faculdade de Economia, Administração e Contabilidade, São Paulo, SP, Brasil ${ }^{1}$ 


\title{
Resumo
}

Fusões e Aquisições (F\&A) é um assunto extensamente estudado na literatura internacional de finanças. Uma questão em aberto é o papel e impacto da participação de um advisor para auxiliar no processo de negociação. A literatura concentra-se no estudo do mercado americano com características diferentes de um mercado emergente com firmas de propriedade concentrada. Utilizando dados de 7.302 operações brasileiras, este artigo investiga o papel da presença de advisors no tempo de negociação e a taxa de sucesso, bem como identifica características das transações que sejam determinantes para sua participação. Por meio de regressão linear e logística, constatou-se que as transações que contam com a participação de advisors têm (a) um maior tempo de transação, tradicionalmente associado a eles terem um papel ativo, (b) uma maior taxa de sucesso. Adicionalmente, constatou-se que a probabilidade de participação de um advisor aumenta com a complexidade e porte do negócio, com a experiência anterior com F\&A da adquirente e quando o pagamento é totalmente em ações.

Palavras-chave: M\&A; advisor; papel.

\begin{abstract}
Mergers and Acquisitions (M\&A) is a widely studied subject in finance. A question that remains unanswered is the role and impact of the advisor's choice in the process of acquiring or merging. The current literature focuses on studying the US market/developed countries with different characteristics of an emerging market oriented toward the ownership of firms. Using data from more than 7,000 operations, this paper investigates the role of advisors in the negotiation and success rate and seeks to determine the characteristics for their participation. Linear and logistic regression revealed that the advisors play an active role due to the significantly longer period between the announcement and conclusion of the deal in which they participated. We also identified a higher success rate in comparison with in-house deals. Regarding the determinants, complexity, size of the deal, the acquirer's previous experience in M\&A, and payment entirely in shares increases the probability of hiring an advisor.
\end{abstract}

Keywords: M\&A; Advisor; Role

JEL Codes: G34, G24, N26. 


\section{Introdução}

Dentro das finanças corporativas, no dia a dia do Chief Executive Officer (CEO), uma das decisões mais importantes é a de quando e como efetuar uma fusão ou aquisição de outra companhia, já que, segundo Bao e Edmans (2011), uma decisão acertada pode criar uma sinergia substancial e uma decisão errônea pode levar a alocações indevidas de capital e consequente diminuição da riqueza dos acionistas.

No Brasil, no período de janeiro de 1994 até junho de 2016, foram efetuados mais de 7.000 (sete mil) anúncios de fusões e aquisições (F\&A) segundo a base de dados THOMSON REUTERS SDC, totalizando mais de 700 bilhões de dólares em negócios. Todavia, dentro da academia brasileira, a disseminação de estudos nesta área é incipiente, Leal, Almeida e Bortolon (2013) constataram que da literatura de finanças nacional, apenas oito estudos que ensejam esta seara foram publicados. A maioria dos estudos anteriores buscam relacionar F\&A e valor, entretanto, na academia internacional, ele é extensamente estudado no contexto do mercado americano, sob várias abordagens, desde a criação/destruição de valor, até o papel do advisor, de auxiliar a firma na avaliação dos ativos e passivos da empresa, como também na forma de pagamento, caso a adquirente decida pelo pagamento por meio de instrumentos patrimoniais.

Em comparação a outros campos de estudos de F\&A, as determinantes da escolha entre advisors foram relativamente pouco estudadas. Servaes e Zenner (1996), Hunter e Jagtiani (2003), Forte, Iannotta e Navone (2010), Bao e Edmans (2011), Golubov, Petmezas e Travlos (2012), Song, Wei e Zhou (2013), Derrien e Dessaint (2018) pesquisaram essa seara utilizando dados majoritariamente do mercado americano ou mercados desenvolvidos.

Duas razões são dadas como justificativas da participação dos advisors: aquisições hostis; e o efeito de certificação atribuído pela sua presença perante aos acionistas (em vista da propriedade dispersa presente em mercados desenvolvidos), Thomas (1995) argumenta que a contratação teria como função garantir/certificar que aquela transação tem como objetivo aumentar a riqueza do acionista.

No mercado brasileiro, dos 7.300 anúncios, apenas 1.531 contaram com a participação de um advisor, somente uma transação foi classificada como hostil e, além disso, o Brasil possui uma estrutura de propriedade extremamente concentrada (Ermel \& Monte, 2018; Leal, Silva, \& Valadares, 2002).

Isto posto, o objetivo desse trabalho é: investigar o papel do advisor nos processos de F\&A e os determinantes de sua participação nos negócios de F\&A no Brasil. Como justificativa para esse estudo está a alta concentração acionária brasileira; da ausência de um mercado efetivo de controle; além de uma base de dados que, dado o conhecimento dos autores, não foi utilizada em outro estudo no país, além de ser a base de dados com maior quantidade de negócios no Brasil. Steinberg e Silva (2009) justificaram os poucos estudos no país devido à dificuldade em conseguir base de dados.

Os resultados encontrados sugerem que, no Brasil, para os negócios executados por companhias abertas, os advisors têm um papel ativo, em vista da associação positiva entre sua presença e o tempo de negociação, de forma que as transações que contam com sua participação pela parte adquirente, levam em média 30 dias a mais para serem completados do que os negócios realizados in-House (Aquisições realizadas sem o auxílio de um advisor). Possivelmente em razão de um maior número de diligências realizadas por esses agentes, ou devido o contratante perceber uma maior dificuldade na operação e, dessa forma, escolher pela sua contratação para contar com sua expertise.

Em relação à taxa de sucesso, os negócios com presença de um advisor tem um aumento médio de probabilidade de aproximadamente $10 \%$ de serem concluídos, quando comparados aos negócios que não contam com sua presença. E, assim, é possível que no cenário brasileiro, os advisors também sejam motivados pelo sentimento de empire building (Rau, 2000). Outra explicação possível é a sua 
especialização, o que pode levar a indicar/selecionar melhores negócios para participar, e com maior chance de serem concluídos (Hunter \& Jagtiani, 2003).

Quanto às características dos negócios, o advisor está presente em negócios de maior porte, maior experiência do adquirente e pagamento utilizando ações. Não se pôde confirmar a hipótese de assimetria informacional, medida pela aquisição de firma de setor diferente da adquirente.

Desta forma, este artigo contribui para literatura nacional e internacional ao evidenciar que, mesmo na ausência de um mercado efetivo de controle e propriedade concentrada, a contratação de um advisor está ligada a características de transações, como custos de transação e custos de agência. Além disso, exibem um papel ativo estarem positivamente correlacionados com o tempo de transação e também com maior taxa de sucesso (conclusão).

Além desta introdução, este artigo tem a seguinte sequência, referencial teórico, onde se busca fundamentar a teoria e elencar os estudos anteriores realizados nesta área. Em seguida, a metodologia busca detalhar o processo metodológico utilizado no presente estudo. Posteriormente são apresentados e discutidos os resultados e ao final apresentam-se as considerações finais.

\section{Referencial Teórico}

\section{Função e determinantes da participação de advisors}

$\mathrm{Na}$ literatura bancária e de intermediários financeiros, é conhecido o fato de que a existência desses participantes tem seu cerne nos custos de transação e na economia de escala, de forma que, diferentemente de firmas individuais, os intermediários financeiros concentram especialização e, dessa forma, conseguem ganho de escala e diminuição de custos, já que a atividade de verificação e monitoramento será realizada com maior eficiência, como proposto por Scholes, Benston e Smith (1976).

Servaes e Zenner (1996) buscaram definir um arcabouço teórico sobre os possíveis motivos do CEO optar por contratar um advisor para auxiliar a firma em um processo de F\&A ou por realizar o processo por conta própria. Servaes e Zenner (1996) elaboraram 3 hipóteses para a participação de um advisor em um processo de F\&A: Custos de transação, Informação assimétrica e Custos contratuais.

Benston e Smith (1976) teorizam que custos de transação são as razões pelas quais os intermediários financeiros têm vantagem comparativa quanto à produção de serviços financeiros. Eles iriam trazer benefícios à transação devido a economia de especialização, ganhos de escala e redução nos custos. Assim, o advisor pode procurar um bom alvo para a aquisição, realizar o apreçamento a um custo menor do que as firmas de forma individual. Dessa forma, de acordo com Servaes e Zenner (1996) é esperado que firmas envolvidas com maiores custos de transação sejam mais propensas a procurar assessoramento desses intermediários.

Isto posto, é comum na literatura (Golubov, Petmezas, \& Travlos, 2012; Servaes \& Zenner, 1996) considerar transações de maior valor, pagas com títulos, e adquirente com menor experiência em F\&A, possuam maiores custos de transação do que as transações menores, pagas somente com caixa e onde o adquirente possua um maior know how.

Assim, quanto à participação na transação temos a hipótese 1 do estudo.

H1. A presença de advisors é positivamente correlacionada com características que sugerem uma maior existência de custos de transação.

Outro possível determinante é a assimetria informacional entre a firma adquirente e a firma alvo, adquirentes iriam procurar por auxílio em aquisições de ativos específicos e/ou de difícil 
avaliação, por exemplo, em aquisições de firmas fechadas (sem informação prontamente avaliada e disponível, além de não ter o escrutínio do mercado). Baseado no trabalho de Servaes e Zenner (1996), consideramos que há uma maior assimetria de informações quando adquirente e alvo operam em setores diferentes, e menor quando operam no mesmo setor.

Isto posto, temos a hipótese 2 do estudo.

H2. A presença de advisors é positivamente correlacionada com características que sugerem uma maior existência de assimetria informacional.

Custos contratuais (de agência) também estariam relacionados a sua presença, Easterbrook (1984) denota o papel de certificação do advisor frente aos investidores nas emissões de ações e dívidas, partindo da lógica que os advisors têm incentivos para monitorar o emissor e garantir um bom investimento para seus clientes. Servaes e Zenner (1996) extrapolam esse pensamento para o mercado de F\&A, o qual, por meio do ganho de escala e de maior conhecimento para identificar e auxiliar a firma em bons negócios, certificariam para o acionista a qualidade da transação.

H3. A presença de advisros é positivamente correlacionada com características que sugerem maiores custos de agência.

Outras dimensões também foram adicionadas como determinantes de sua participação como: aconselhamento estratégico, proposto por Kale, Kini e Ryan (2003); ou a função de encontrar negócios mais vantajosos e com uma maior sinergia, como exposto por Bao e Edmans (2011).

\section{Advisors e F\&A}

A maior parte da literatura relacionada à presença dos advisors em F\&A é voltada para a seguinte questão: a participação de um advisor resulta em criação de valor para o acionista adquirente?. Bowers e Miller (1990) argumentam que os advisors toptiers (aqueles com uma maior reputação) são capazes de encontrar melhores negócios para o cliente, entretanto, não conseguem traduzir isso em riqueza para o acionista.

Rau (2000) demonstra que os toptiers têm menor taxa de sucesso na conclusão dos negócios e que, ao considerar as taxas cobradas pelo serviço de assessoramento, os negócios com sua participação têm uma pior performance pós-aquisição quando comparados aos advisors com menor reputação. E Cornaggia e Rau (2002) evidenciam que os não toptiers estão associados a um maior retorno anormal no anúncio do negócio.

Servaes e Zenner (1996) identificam que a presença do advisor se dá em negócios de maior complexidade e quando a firma adquirente possui pouca experiência anterior em aquisições.

Kisgen e Song (2009) demonstram que no período de 1994-2004, nos USA, mesmo acompanhados por advisors nas transações, $37 \%$ dos adquirentes solicitaram uma fairness opinion, que é um processo onde uma das partes da transação requer uma terceira opinião sobre alguma característica da transação. A grande maioria dos pedidos de fairness opinion são para a discussão do valor a ser pago pelo adquirente da transação

Derrien e Dessaint (2018) investigam como a reputação do advisor, utilizando como proxy uma league table afetam o mercado de $\mathrm{F} \& \mathrm{~A}$, os autores encontram que a posição no ranking influencia os fluxos de caixas relativos a negócios futuros, e também que, para melhorar sua colocação, os advisors reduzem suas fees.

Bi e Wang (2018) investigam a participação de advisors toptiers nos negócios de F\&A chineses, e identificam que sua participação está correlacionada com o futuro desempenho operacional da firma, e também com a criação de valor para o acionista. 
Francis, Hasan e Sun (2014) ressaltam a importância da experiência do adquirente na decisão de contratação ou não, já que adquirentes menos experientes optariam pela contratação de advisors, especialmente em transaçõesas quais o pagamento seja por meio de ações.

Assim, a participação de advisors nas transações pode se dar de duas maneiras. A primeira é ativa, procurando bons alvos para a firma adquirente, a segunda é, à medida que a adquirente já escolheu a empresa a ser adquirida, o advisor executa um papel de conselheiro, executando o valuation, realizando a due dilligence, emitindo opinião acerca da transação e também, se necessário, organizando a emissão de títulos para a realização do pagamento. Dessa forma, a participação de advisors mostra-se, num primeiro momento, fundamental. Entretanto, como demonstrado anteriormente, estudos discutem se sua presença de fato agrega valor ou se é apenas uma certificação para os acionistas.

Ademais, Guo, Li, Wang e Xing (in press) identificam que negócios com a participação de advisors toptier estão relacionados a uma melhor performance pós F\&A de firmas consideradas restritas.

Bhattacharya, Hsu, Li e Liu (in press) investigam as razões pelas quais alguns adquirentes optam por contratar o advisor que auxiliou uma firma alvo em operação anterior, os autores encontram que esse fenômeno está relacionado com a reputação do investment bank e se executou um serviço de excelência (mensurado como o retorno anormal da firma alvo no momento do anúncio).

\section{Fusões e aquisições no Brasil}

No Brasil, o estudo bibliométrico realizado por Leal et al. (2013) evidenciou os poucos estudos realizados na área. Camargos e Barbosa (2006) verificaram a criação de valor para o acionista no processo de F\&A utilizando a metodologia de estudo de eventos. Concluíram que os processos não resultavam em criação de valor para o acionista. Este resultado corroborou o estudo anterior de Brito, Batistella e Famá (2005).

Pasin e Martelanc (2017) destacam que, no Brasil, existem consultores, boutiques, bancos de investimento e empresas de auditoria que possuem especialização em um ou mais passos de uma fusão e aquisição, como o valuation, negociação, due dilligence, diagnóstico da empresa alvo, entre outros. Os autores destacam que muitos desses listados acima permanecem por longa data auxiliando as empresas.

\section{Metodologia}

A base de dados utilizada no estudo foi a Thomson Reuters SDC, no período de janeiro de 1994 até junho de 2016. A escolha foi decidida em razão da estabilidade trazida pelo Plano Real e disponibilidade relativa à padronização dos balanços publicados pelas empresas.

Com o intuito de verificar o papel dos advisors no mercado brasileiro de $\mathrm{F} \& \mathrm{~A}$, foram estimados os seguintes modelos:

$$
\begin{gathered}
\text { LnTempo }=\alpha+\beta_{1} \text { Advisor }+\beta_{2} \text { LnValor }+\beta_{3} \text { Capital Estrangeiro }+\beta_{4} \text { Setor }+ \\
\beta_{5} \text { LnExpGeral }+\beta_{6} \text { LnExpSemBanco }+\beta_{7} \text { AllStock }+\beta_{8} \text { Allcash }+\beta_{9} \text { LnAt }+\epsilon \\
\text { Completo }=\alpha+\beta_{1} \text { Advisor }+\beta_{2} \text { LnValor }+\beta_{3} \text { Capital Estrangeiro }+\beta_{4} \text { Setor }+ \\
\beta_{5} \text { LnExpGeral }+\beta_{6} \text { LnExpSemBanco }+\beta_{7} \text { AllStock }+\beta_{8} \text { Allcash }+\beta_{9} \text { LnAt }+\epsilon \\
\text { Advisor }=\alpha+\beta_{1} \text { LnValor }+\beta_{2} \text { Capital Estrangeiro }+\beta_{3} \text { Setor }+\beta_{4} \text { LnExpGeral }+ \\
\beta_{5} \text { LnExpSemBanco }+\beta_{6} \text { AllStock }+\beta_{7} \text { Allcash }+\beta_{8} \text { LnAt }+\epsilon
\end{gathered}
$$


O Modelo 1 tem como objetivo verificar se a presença de um advisor impacta na duração da transação, ou seja, se o tempo decorrido entre a data de anúncio e a data de conclusão do negócio sofre influência de sua presença; o propósito do modelo 2 é identificar se negócios com sua presença tem maior chance de serem concluídos; e o Modelo 3 busca identificar os fatores determinantes da sua contratação por parte da companhia adquirente.

A variável LnTempo é o logaritmo natural da diferença entre a data de anúncio do negócio e a data de conclusão. Advisor é uma variável dummy de valor 1 caso a negociação tenha o auxílio de um advisor por parte da adquirente e 0 , caso contrário. LnValor é o logaritmo natural do valor total pago pela adquirente na negociação e busca controlar para complexidade, relevância e exposição do negócio, além de ser proxy para os custos de transação (Servaes \& Zenner, 1996).

Completo é variável dummy com valor 1 caso a F\&A tenha sido efetivada, 0 , caso contrário. CapitalEstrangeiro é variável dummy com valor 1 caso o controlador da companhia adquirente seja estrangeiro, 0 caso contrário, e busca capturar se diferenças de cultura entre o comprador e o adquirente exercem influência (Erel, Liao, \& Weisbach, 2012).

Setor é variável dummy com valor 1 caso a adquirente atue no mesmo setor da companhia adquirida e 0 , se os setores de atuação da companhia adquirente e da adquirida forem diferentes, de forma a controlar pela assimetria informacional entre o adquirente e a adquirida (Servaes e Zenner, 1996).

LnExpGeral é o logaritmo natural do número de F\&A realizados pela adquirente até a presente negociação do tempo t, devido a possível existência de relacionamento entre o adquirente e a contratação de um ou mais advisors (Golubov et al. 2012). LnExpSemBanco é o logaritmo natural do número de $\mathrm{F} \& \mathrm{~A}$ realizados até o tempo $\mathrm{t}$ sem a presença de um advisor, assim, controla-se para a experiência do adquirente em negócios in-house e possível criação de departamentos de F\&A dentro das firmas, além de também mensurarem custos de transação (Golubov et al. 2012).

AllStock é variável dummy com valor 1 caso o pagamento tenha sido realizado apenas com ações, 0 caso contrário. AllCash é variável dummy com valor 1 caso o pagamento tenha sido realizado apenas com caixa, 0 caso contrário, ambas as variáveis AllStock e AllCash buscam controlar para complexidades nos negócios, pois negócios pagos em ações são geralmente mais complexos (Servaes \& Zenner, 1996).

LnAt é o logaritmo natural do total do ativo da adquirente, quando disponível, com o intuito de controlar a exposição e relevância da firma adquirida, e também complexidade do negócio (Golubov et al.2012; Servaes \& Zenner, 1996). Como em muitos dos negócios, o total do ativo da adquirente não é evidenciado, serão estimados os modelos 1,2 e 3 com e sem a presença dessa variável.

Também é importante ressaltar que todos as equações foram controladas pelo tipo de transação, e que essas variáveis foram suprimidas em razão de espaço.

\section{Análise de Dados}

A base de dados totaliza 7.302 anúncios de negócios, dos quais 5.575 foram concluídos. Em 1.531 (21\% do total) negócios houve a participação de um advisor por parte do adquirente, participação baixa quando comparado a estudos anteriores realizados no mercado americano i.e Servaes e Zenner (1996), onde houve participação em aproximadamente 70\% da amostra e Golubov et al., (2012) na qual o percentual chegou a 91, todavia, esses estudos utilizaram majoritariamente amostras compostas de aquisições realizadas por firmas com instrumentos patrimoniais negociados em Bolsa de Valores. 
$\mathrm{Na}$ amostra do presente estudo, 2.290 anúncios de negociações foram realizados por firmas com o capital aberto no período da aquisição, e 5.012 por firmas de capital fechado. Advisors estiveram presentes em 676 (29\%) negociações envolvendo adquirentes com o capital aberto e 855 (17\%) em firmas de capital fechado.

A literatura recente atribuiu importância a reputação do advisor em relação a sua participação e quanto ao seu papel dentro da negociação (Bao \& Edmans, 2011; Golubov et al., 2012; Servaes \& Zenner, 1996). Por isso, nesse estudo serão considerados advisors toptiers os que participaram em, no mínimo, 30 negócios, seja como principal ou como componente de um sindicato, e a soma dos negócios em que participou seja maior que 1 bilhão de dólares. Os considerados toptiers estão listados na Tabela 1, junto ao número de negócios e valor total.

Tabela 1

\section{Descrição, Classificação e Ranking de Advisors Toptier}

\begin{tabular}{|c|c|c|c|}
\hline Banco/Consultoria & \#Negócios Completos & Valor Negócios (\$ mi) & Categoria \\
\hline Rothschild & 56 & 42264,30864 & $\mathrm{c} 1$ \\
\hline Banco Itaú as & 186 & 41480,62635 & b1 \\
\hline Credit Suisse & 112 & 36594,61591 & b1 \\
\hline JP MORGAN & 74 & 35366,72918 & b1 \\
\hline Citi & 53 & 28676,12291 & b1 \\
\hline Banco BTG Pactual SA & 126 & 26677,59105 & b1 \\
\hline Banco Santander SA & 63 & 24611,20535 & b1 \\
\hline Banco Bradesco as & 128 & 23972,60128 & b1 \\
\hline Morgan Stanley & 55 & 23264,9807 & b1 \\
\hline Goldman Sachs \& Co & 64 & 19652,26212 & b1 \\
\hline Merril Lynch & 47 & 17868,7517 & b1 \\
\hline UBS Investment Bank & 44 & 16144,19675 & b1 \\
\hline ABN AMRO & 42 & 11596,64088 & b1 \\
\hline BR Partners & 37 & 2699,86047 & $\mathrm{c} 1$ \\
\hline KPMG & 31 & 2031,3565 & $\mathrm{c} 1$ \\
\hline PWC & 39 & 1795,4842 & $\mathrm{c} 1$ \\
\hline
\end{tabular}

Nota. Classificação dos advisors toptiers, estes são os que participaram em, no mínimo, 30 negócios, seja como principal advisor ou como componente de um sindicato, e a soma dos negócios em que participou seja maior que 1 bilhão de dólares. Na coluna 2 está disposto o número de negócios que tiveram sua participação. Na coluna 3 está a soma nominal dos valores dos negócios que envolveram sua participação. A última coluna representa a categoria do advisor, c1 representa uma consultoria toptier, b1 representa um banco toptier. Fonte: Elaborado pelos autores a partir da base de dados da Thomson Deal Scanner [Annual Data]. (1994-2016). Available: Thomson Reuters SDC [Apr/2017].

Os advisors foram divididos em duas categorias, c1, que representa uma consultoria toptier, e b1, que representa um banco toptier, essa classificação segue os critérios de Allen, Jagtiani, Peristiani e Saunders (2004), que demonstraram as diferenças entre investment bank e não investment bank quanto a participação e eficiência na negociação.

Dentro dos 16 listados, somente 4 são de origem brasileira: Banco Itaú SA, Banco BTG Pactual SA, Banco Bradesco SA e BR Partners. Estes totalizam 94.830 bilhões de dólares em negociação, ou seja, participaram de $26 \%$ das negociações assessoradas por um banco/consultoria de primeira linha no 
quesito valor. Em relação à quantidade de negócios, esta proporção aumenta para 41\%, dentro de um total de 447 negociações. Esses dados indicam que os advisors brasileiros apesar de participarem de um número maior de negócios, estes não são os de maior valor.

A Figura 1 demonstra a evolução temporal na quantidade de negócios no período de 1994 a 2016. É possível notar um pequeno aumento no número de F\&A de 1998 a 2001, chegando a quase 300 negócios anunciados em 2000, com relativa estabilização, até o acontecimento de outro boom, a partir de 2007, com pico em 2008, onde mais de 700 negócios foram anunciados e mais de 600 foram concluídos, e decrescimento dali em diante. A coluna verde, que representa o número de negócios com a participação de um advisor, evidencia que apenas uma pequena parte das negociações são assessoradas por um banco/consultoria.
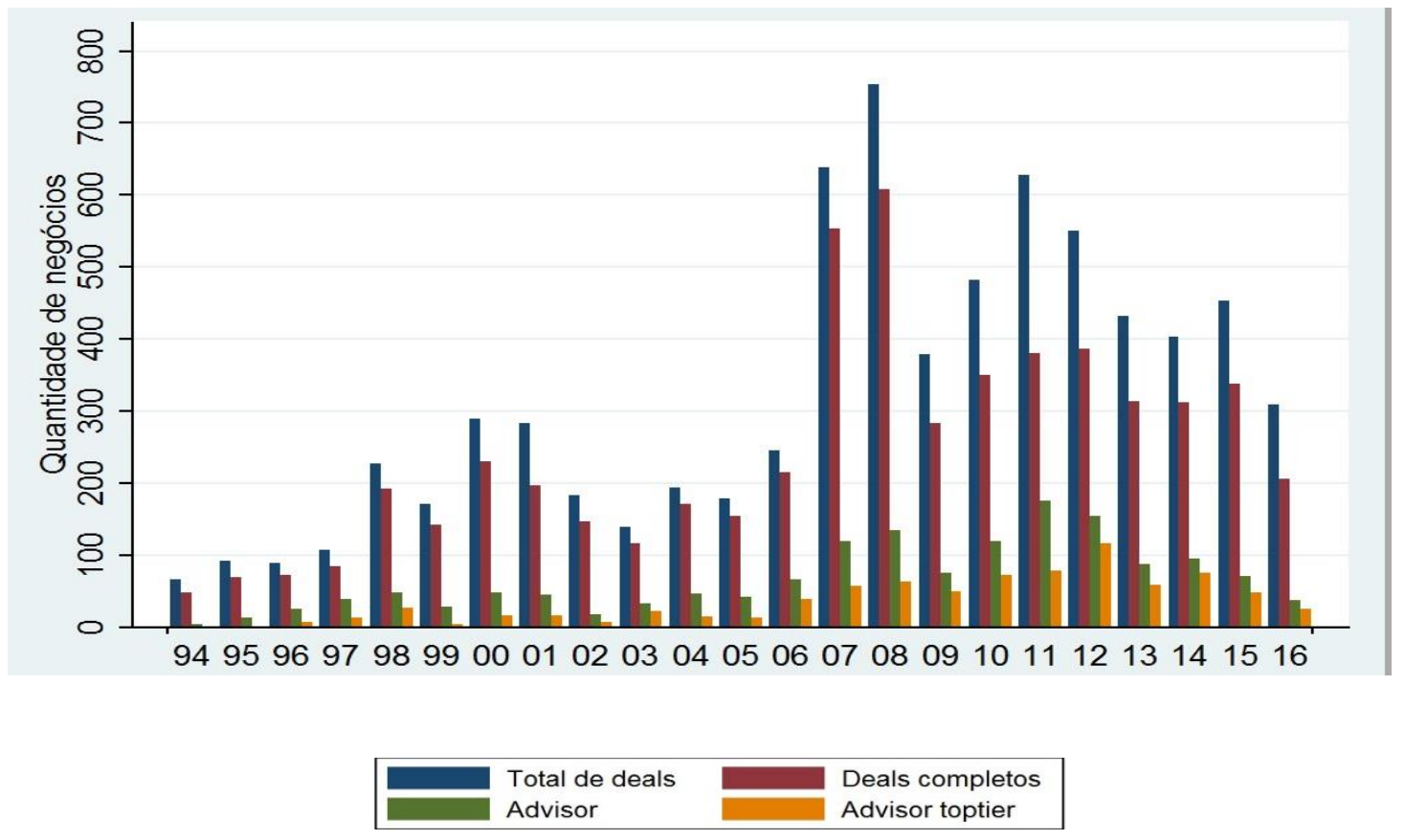

Figura 1. Evolução Temporal de Fusões e Aquisições no Brasil. 1994 a 2016

Fonte: Fonte: Elaborado pelos autores a partir da base de dados da Thomson Deal Scanner [Annual Data]. (1994-2016). Available: Thomson Reuters SDC [Apr/2017].

A Tabela 2 exibe a média, desvio padrão e quantidade de negócios da presente amostra, dividida em quatro categorias: amostra total, advisors, in-house e toptier. $\mathrm{O}$ valor médio pago pelos adquirentes da amostra total é de 240 milhões de dólares, esse número sobe para 538 milhões quando o negócio tem a presença de um advisor e desce para 96 milhões quando considerados apenas os negócios executados sem auxílio de banco ou consultoria. A amostra de toptiers exibe o maior valor, com 729 milhões de média. 
Tabela 2

Estatística Descritiva entre Amostras. 1994 a 2016

\begin{tabular}{|c|c|c|c|c|c|c|c|c|c|c|c|c|}
\hline \multirow[b]{2}{*}{ Variável } & \multicolumn{3}{|c|}{ Amostra Total } & \multicolumn{3}{|c|}{ Advisors } & \multicolumn{3}{|c|}{ In-house } & \multicolumn{3}{|c|}{ Toptier } \\
\hline & $\mathrm{N}$ & Média & Desv.Pad. & $\mathrm{N}$ & Média & Desv.Pad. & $\mathrm{N}$ & Média & Desv.Pad. & $\mathrm{N}$ & Média & Desv.Pad. \\
\hline Valor Negócio & 3268 & 240.2 & 1070 & 1062 & 538.9 & 1787 & 2206 & 96.37 & 308.3 & 612 & 729.8 & 2293 \\
\hline Completo & 3268 & 0.75 & 0.43 & 1062 & 0.85 & 0.38 & 2206 & 0.70 & 0.46 & 612 & 0.83 & 0.38 \\
\hline Aberta & 3268 & 0.43 & 0.45 & 1062 & 0.49 & 0.50 & 2206 & 0.40 & 0.49 & 612 & 0.47 & 0.50 \\
\hline Tempo & 2444 & 72.10 & 167.5 & 903 & 111.9 & 194.3 & 1541 & 48.78 & 144.7 & 507 & 127.1 & 211.1 \\
\hline CapitalEstrangeiro & 3268 & 0.18 & 0.39 & 1062 & 0.22 & 0.42 & 2206 & 0.17 & 0.37 & 612 & 0.19 & 0.39 \\
\hline Setor & 3268 & 0.42 & 0.50 & 1062 & 0.39 & 0.49 & 2206 & 0.44 & 0.50 & 612 & 0.38 & 0.49 \\
\hline ExpGeral & 3268 & 15.96 & 52.96 & 1062 & 15.94 & 50.50 & 2206 & 15.97 & 54.12 & 612 & 18.81 & 56.95 \\
\hline ExpSemBanco & 3268 & 11.63 & 40.00 & 1062 & 10.10 & 38.04 & 2206 & 12.37 & 40.90 & 612 & 12.33 & 43.04 \\
\hline Mixednegócios & 3268 & 0.54 & 0.50 & 1062 & 0.56 & 0.50 & 2206 & 0.53 & 0.50 & 612 & 0.54 & 0.50 \\
\hline AllCash & 3268 & 0.42 & 0.49 & 1062 & 0.34 & 0.47 & 2206 & 0.46 & 0.50 & 612 & 0.36 & 0.48 \\
\hline AllStock & 3268 & 0.04 & 0.20 & 1062 & 0.10 & 0.30 & 2206 & 0.02 & 0.13 & 612 & 0.11 & 0.31 \\
\hline AcqCertAsts & 3268 & 0.00 & 0.035 & 1062 & 0.00 & 0.03 & 2206 & 0.00 & 0.04 & 612 & 0 & 0 \\
\hline AcqMajInt (AMI) & 3268 & 0.19 & 0.39 & 1062 & 0.20 & 0.40 & 2206 & 0.19 & 0.39 & 612 & 0.19 & 0.39 \\
\hline AcqPartInt (API) & 3268 & 0.21 & 0.41 & 1062 & 0.20 & 0.40 & 2206 & 0.21 & 0.41 & 612 & 0.20 & 0.40 \\
\hline AcqRemInt & 3268 & 0.08 & 0.27 & 1062 & 0.11 & 0.32 & 2206 & 0.06 & 0.24 & 612 & 0.11 & 0.31 \\
\hline Acqofassets (AA) & 3268 & 0.23 & 0.42 & 1062 & 0.19 & 0.40 & 2206 & 0.25 & 0.43 & 612 & 0.20 & 0.40 \\
\hline Acquisition & 3268 & 0.00 & 0.06 & 1062 & 0 & 0 & 2206 & 0.01 & 0.08 & 612 & 0 & 0 \\
\hline Buyback & 3268 & 0.09 & 0.28 & 1062 & 0.01 & 0.10 & 2206 & 0.12 & 0.33 & 612 & 0.01 & 0.11 \\
\hline Exchange Offerr & 3268 & 0.00 & 0.017 & 1062 & 0 & 0 & 2206 & 0.00 & 0.02 & 612 & 0 & 0 \\
\hline Merger & 3268 & 0.20 & 0.40 & 1062 & 0.28 & 0.45 & 2206 & 0.16 & 0.37 & 612 & 0.30 & 0.46 \\
\hline Recapitalizationn & 3268 & 0.00 & 0.01 & 1062 & 0 & 0 & 2206 & 0.00 & 0.02 & 612 & 0 & 0 \\
\hline
\end{tabular}

Nota. Fonte: Elaborado pelos autores a partir da base de dados da Thomson Deal Scanner [Annual Data]. (1994-2016). Available: Thomson Reuters SDC [Apr/2017].

Ao considerar a taxa de sucesso, $74 \%$ dos negócios chegam a ser finalizados na amostra total, com um aumento para $85 \%$ na amostra com a participação de advisors e redução para $69,9 \%$ para os negócios In-house. Cerca de 50\% são pagos totalmente em espécie e $34 \%$ são os chamados diversifying deals, cuja adquirida não pertence ao mesmo setor da adquirente.

Também é possível verificar que o tempo é maior na amostra de toptiers, seguido pela amostra de advisors e In-house, respectivamente. Essa mesma ordem ocorre para o total do ativo das empresas, cuja amostra toptier tem um ativo médio de 30 milhões, enquanto os negócios auxiliados por advisors tem uma média 25 milhões, e a média do total do ativo das empresas que fazem os negócios In-house é de apenas 16 milhões.

Em relação aos tipos de negócios, dentro da amostra, os mais comuns são Acquisition de majority interest (AMI), Acquisition of Partial Interest (API), Acquisition of Assets (AA) e Mergers. A fim de ser classificado como AMI, o adquirente tem que possuir menos que $50 \%$ da empresa e objetivar adquirir mais que $50 \%$, porém, menos que $100 \%$. Já para caracterizar API, não pode haver 
mudança de controle, ou seja, o adquirente deve possuir menos que $50 \%$ da empresa e objetivar possuir menos que $50 \%$, ou mais que $50 \%$ e procurar possuir menos que $100 \%$. A classificação AA é atribuída quando uma firma adquire os ativos de uma companhia, subsidiaria ou departamento. Merger consiste quando uma nova companhia é formada por uma junção de duas outras companhias, ou quando ocorre a aquisição de 100\% das ações. (Golubov et al., 2012)

\section{Tempo de conclusão}

A literatura aponta que o advisor pode impactar tanto na redução do tempo da negociação, quanto no aumento. Hunter e Jagtiani (2003) e Golubov et al. (2012) argumentam que devido sua expertise, este pode reduzir o tempo da negociação, entretanto, também é razoável crer que ele seja contratado para exercer as diligências na adquirida, assim, negociações com sua presença levariam mais tempo para serem concluídas.

Além disso, aquisições malsucedidas devido a informações anteriores à aquisição podem impactar negativamente na sua reputação e consequentemente na sua fatia de mercado (Rau, 2000).

A Tabela 3 resume a fundamentação teórica e o sinal esperado das variáveis incluídas no modelo 1.

Tabela 3

\section{Resumo do Esperado em Relação ao Tempo de Negociação}

\begin{tabular}{|c|c|c|c|}
\hline Variável & Sinal esperado & Fundamentação teórica & Referências \\
\hline Acquirer Bank & Indefinido & $\begin{array}{l}\text { Redução devido à expertise ou aumento devido } \\
\text { a uma quantidade maior de diligências. }\end{array}$ & $\begin{array}{l}\text { Hunter e Jagtiani (2003) } \\
\text { e Golubov et al. (2012) }\end{array}$ \\
\hline TopTierf & - & $\begin{array}{l}\text { Maior eficiência e consequentemente um menor } \\
\text { tempo. }\end{array}$ & $\begin{array}{l}\text { Hunter e Jagtiani (2003) } \\
\text { e Golubov et al. (2012) }\end{array}$ \\
\hline TopTier BR & + & Menor tempo devido a um fator cultural. & $\begin{array}{l}\text { Hunter e Jagtiani (2003) } \\
\text { e Golubov et al. (2012) }\end{array}$ \\
\hline ToptierEstrangeiro & - & $\begin{array}{l}\text { Menor tempo devido a uma maior eficiência e } \\
\text { expertise. }\end{array}$ & $\begin{array}{l}\text { Hunter e Jagtiani (2003) } \\
\text { e Golubov et al. (2012) }\end{array}$ \\
\hline LnValor & + & $\begin{array}{l}\text { Devido a uma maior complexidade, relevância e } \\
\text { exposição, espera-se um maior tempo. }\end{array}$ & $\begin{array}{l}\text { Servaes e Zenner (1996), } \\
\text { Golubov et al. (2012) }\end{array}$ \\
\hline CapitalEstrangeiro & + & $\begin{array}{l}\text { Devido a barreiras culturais, espera-se um maior } \\
\text { tempo de conclusão. }\end{array}$ & $\begin{array}{l}\text { Erel, Liao e Weisbach } \\
\text { (2012) }\end{array}$ \\
\hline Setor & - & $\begin{array}{l}\text { Espera-se um menor tempo de conclusão } \\
\text { quando adquirente e adquirida atuem num } \\
\text { mesmo setor. Devido a uma menor assimetria de } \\
\text { informação. }\end{array}$ & $\begin{array}{l}\text { Servaes e Zenner (1996), } \\
\text { Golubov et al. (2012) }\end{array}$ \\
\hline LnExpGeral & - & $\begin{array}{l}\text { Espera-se que uma maior experiência em } \\
\text { negócios diminua o tempo de conclusão devido } \\
\text { ao ganho de aprendizado. }\end{array}$ & $\begin{array}{l}\text { Servaes e Zenner (1996), } \\
\text { Golubov et al. (2012) }\end{array}$ \\
\hline LnExpSemBanco & - & $\begin{array}{l}\text { Espera-se que uma maior experiência em } \\
\text { negócios sem o acompanhamento de um advisor } \\
\text { diminua o tempo de conclusão devido ao ganho } \\
\text { de aprendizado. }\end{array}$ & $\begin{array}{l}\text { Servaes e Zenner (1996), } \\
\text { Golubov et al. (2012) }\end{array}$ \\
\hline
\end{tabular}


Tabela 3 (continuação)

\begin{tabular}{|c|c|c|c|}
\hline Variável & Sinal esperado & Fundamentação teórica & Referências \\
\hline AllStock & + & $\begin{array}{l}\text { Negócios pagos com ações têm uma maior } \\
\text { complexidade devido à necessidade de } \\
\text { avaliação e até emissão de novas ações, assim, } \\
\text { espera-se que negócios pagos dessa forma } \\
\text { demorem mais tempo. }\end{array}$ & $\begin{array}{l}\text { Servaes e Zenner (1996), } \\
\text { Golubov et al. (2012) }\end{array}$ \\
\hline AllCash & - & $\begin{array}{l}\text { Negócios pagos com caixa tem uma menor } \\
\text { complexidade, assim, espera-se uma redução no } \\
\text { tempo de conclusão. }\end{array}$ & $\begin{array}{l}\text { Servaes e Zenner (1996), } \\
\text { Golubov et al. (2012) }\end{array}$ \\
\hline LnAt & + & $\begin{array}{l}\text { Quão maior for o alvo, maior a complexidade e } \\
\text { exposição do negócio, dessa forma, espera-se } \\
\text { que quanto maior, maior seja o tempo de } \\
\text { negociação. }\end{array}$ & $\begin{array}{l}\text { Servaes e Zenner (1996), } \\
\text { Golubov et al. (2012) }\end{array}$ \\
\hline
\end{tabular}

Dessa forma, foi estimado o modelo 1, presente na Tabela 4, na qual a variável dependente é o logaritmo natural do tempo (em dias) decorrido entre a data de anúncio e a data de conclusão. Nessa estimação, foram considerados apenas negócios completados, além da amostra ser composta apenas de operações onde a adquirente é companhia listada em bolsa. Golubov et al. (2012) argumentam que muitos dos negócios realizados por companhias não listadas são anunciados e concluídos no mesmo dia, devido a não obrigação de fornecer informação tempestiva e correta a investidores externos.

Tabela 4

Influência do Advisor na Duração da Negociação

\begin{tabular}{lcccccccc}
\hline & $(1)$ & $(2)$ & $(3)$ & $(4)$ & $(5)$ & $(6)$ & $(7)$ & $(8)$ \\
& LnTempo & LnTempo & LnTempo & LnTempo & LnTempo & LnTempo & LnTempo & LnTempo \\
\hline \multirow{3}{*}{ Advisor } & $0.292^{*}$ & $0.380^{* *}$ & & & & & & \\
& $(0.160)$ & $(0.178)$ & & & & & & \\
Toptierf & & & 0.165 & 0.188 & & & & \\
& & & $(0.142)$ & $(0.153)$ & & & & \\
toptierbr & & & & & 0.100 & 0.146 & & \\
& & & & & $(0.179)$ & $(0.182)$ & & \\
toptierEstrangeiro & & & & & & & 0.057 & 0.045 \\
& & & & & & & $(0.140)$ & $(0.147)$ \\
LnValor & $0.081^{* *}$ & 0.051 & $0.092^{* * *}$ & $0.070^{*}$ & $0.104^{* * *}$ & $0.085^{* *}$ & $0.101^{* * *}$ & $0.084^{* *}$ \\
& $(0.036)$ & $(0.041)$ & $(0.035)$ & $(0.040)$ & $(0.033)$ & $(0.037)$ & $(0.034)$ & $(0.039)$ \\
CapitalEstrangeiro & $-0.504^{* *}$ & $-0.457^{*}$ & $-0.536^{* *}$ & $-0.498^{* *}$ & $-0.550^{* *}$ & $-0.511^{* *}$ & $-0.561^{* *}$ & $-0.531^{* *}$ \\
& $(0.230)$ & $(0.231)$ & $(0.233)$ & $(0.237)$ & $(0.236)$ & $(0.240)$ & $(0.234)$ & $(0.239)$ \\
Setor & 0.167 & 0.173 & $0.177^{*}$ & $0.191^{*}$ & $0.193^{*}$ & $0.208^{*}$ & $0.186^{*}$ & $0.201 *$ \\
& $(0.107)$ & $(0.112)$ & $(0.107)$ & $(0.111)$ & $(0.106)$ & $(0.111)$ & $(0.108)$ & $(0.113)$ \\
\hline
\end{tabular}


Tabela 4 (continuação)

\begin{tabular}{lcccccccc}
\hline & $(1)$ & $(2)$ & $(3)$ & $(4)$ & $(5)$ & $(6)$ & $(7)$ & $(8)$ \\
& LnTempo & LnTempo & LnTempo & LnTempo & LnTempo & LnTempo & LnTempo & LnTempo \\
\hline LnExpGeral & -0.135 & -0.163 & -0.057 & -0.052 & -0.016 & -0.015 & -0.006 & 0.008 \\
& $(0.138)$ & $(0.145)$ & $(0.121)$ & $(0.126)$ & $(0.131)$ & $(0.139)$ & $(0.122)$ & $(0.131)$ \\
LnExpSemBanco & $0.246^{*}$ & 0.228 & 0.161 & 0.112 & 0.120 & 0.073 & 0.115 & 0.059 \\
& $(0.139)$ & $(0.145)$ & $(0.121)$ & $(0.128)$ & $(0.128)$ & $(0.137)$ & $(0.119)$ & $(0.128)$ \\
AllStock & 0.044 & 0.019 & 0.052 & 0.035 & 0.059 & 0.041 & 0.067 & 0.054 \\
& $(0.163)$ & $(0.170)$ & $(0.161)$ & $(0.168)$ & $(0.166)$ & $(0.172)$ & $(0.160)$ & $(0.169)$ \\
AllCash & -0.102 & -0.105 & -0.107 & -0.111 & -0.108 & -0.111 & -0.105 & -0.109 \\
& $(0.117)$ & $(0.116)$ & $(0.120)$ & $(0.120)$ & $(0.120)$ & $(0.120)$ & $(0.121)$ & $(0.121)$ \\
LnAt & & $0.087 * *$ & & $0.085^{*}$ & & $0.084 *$ & & $0.082^{*}$ \\
Constant & & $(0.043)$ & & $(0.044)$ & & $(0.043)$ & & $(0.044)$ \\
& $4.323 * * *$ & $2.969^{* * *}$ & $4.285^{* * *}$ & $3.194 * * *$ & $4.249 * * *$ & $3.086^{* * *}$ & $4.253 * * *$ & $3.071 * * *$ \\
& $(0.850)$ & $(0.469)$ & $(0.841)$ & $(0.486)$ & $(0.838)$ & $(0.481)$ & $(0.839)$ & $(0.483)$ \\
Observations & & & & & & & & \\
R-squared & 429 & 389 & 429 & 389 & 429 & 389 & 429 & 389 \\
Indústria FE & 0.247 & 0.247 & 0.242 & 0.238 & 0.240 & 0.236 & 0.240 & 0.234 \\
Ano FE & Sim & Sim & Sim & Sim & Sim & Sim & Sim & Sim \\
Tipo de operação & Sim & Sim & Sim & Sim & Sim & Sim & Sim & Sim \\
\hline
\end{tabular}

Nota. Entre parênteses está disposto o erro padrão robusto a heterocedasticidade e agrupado na indústria*ano, e foi estimada a seguinte regressão linear: Lntempo $=\alpha+\beta_{1}$ Acquirerbank $+\beta_{2}$ LnValor $+\beta_{3}$ Capital Estrangeiro $+\beta_{4}$ Setor + $\beta_{5}$ LnExpGeral $+\beta_{6}$ LnExpSemBanco $+\beta_{7}$ AllStock $+\beta_{8}$ Allcash $+\beta_{9}$ LnAt. Todas as equações foram estimadas com efeitos fixos de tempo para controlar os fatores macroeconômicos, efeitos fixos de indústria para controlar as heterogeneidades constantes referente a cada grupo e efeitos fixos de tipo de classificação. Fonte: Elaborado pelos autores a partir da base de dados da Thomson Deal Scanner [Annual Data]. (1994-2016). Available: Thomson Reuters SDC [Apr/2017].

$*=\mathrm{p}<0.01 * *=\mathrm{p}<0.05 * * *=\mathrm{p}<0.10$.

Para o modelo estimado na Tabela 4, a variável advisor foi positiva e significante em todas as equações, apontando que sua presença aumenta o tempo da negociação em comparação aos negócios executados In-house, evidenciando assim um possível comportamento de maior ativismo em razão de maior quantidade de diligências, visto que negócios com sua participação tem uma duração $31 \%$ maior, em média. Apesar do sugerido pela estatística descritiva, os toptiers, tanto brasileiros quanto estrangeiros não exibiram diferença estatística quando comparados aos demais, esse resultado é diferente do encontrado por Hunter e Jagtiani (2003) e sugere que no cenário brasileiro um possível prêmio cobrados por estes não advém de um maior cuidado ou expertise.

Quanto aos controles, o porte do negócio, teve coeficiente positivo em todas as equações, e foi significante a $1 \%$ em 7 das 8 estimações, sugerindo que negócios de maior valor tendem a um maior tempo de negociação devido à complexidade, relevância e exposição. CapitalEstrangeiro mostrou-se com um coeficiente negativo e significante a $5 \%$ em todas as equações, a indicar que firmas de capital nacional levam mais tempo para concluir o negócio mesmo com diferenças culturais (Erel et al. 2012). 


\section{Taxa de sucesso}

Segundo Rau (2000) advisors são movidos por um sentimento de empire building, assim, tem incentivos para aumentar a sua fatia de mercado e sua reputação ajudando a completar o maior número de negócios possíveis. Hunter e Jagtiani (2003) argumentam que a economia de escala e a economia de especialização levam a uma porcentagem maior de sucesso nos negócios auxiliados por advisors.

A Tabela 5 resume a fundamentação teórica e o sinal esperado das variáveis incluídas no modelo 2.

Tabela 5

Resumo Teórico Acerca do Aumento ou Diminuição da Taxa De Sucesso

\begin{tabular}{|c|c|c|c|}
\hline Variável & Sinal esperado & Fundamentação teórica & Referencias \\
\hline Acquirer Bank & + & $\begin{array}{l}\text { Advisors tem motivações para concluir um maior } \\
\text { número de negócios cujo objetivo é aumentar seu } \\
\text { marketshare, também se espera que devido a uma } \\
\text { maior especialização, estes sejam capazes de } \\
\text { indicar ou auxiliar melhor o negócio. }\end{array}$ & $\begin{array}{l}\text { Hunter e Jagtiani } \\
\text { (2003), Golubov et } \\
\text { al. (2012), Rau } \\
\text { (2000), Servaes e } \\
\text { Zenner (1996) }\end{array}$ \\
\hline TopTierf & + & $\begin{array}{l}\text { Advisors toptiers podem ser contratados somente } \\
\text { para finalizar os negócios, e assim, espera-se uma } \\
\text { maior taxa de sucesso. }\end{array}$ & Golubov et al. (2012) \\
\hline TopTier BR & + & Maior taxa de sucesso devido a um fator cultural & $\begin{array}{l}\text { Hunter e Jagtiani } \\
\text { (2003) e Golubov et } \\
\text { al. (2012) }\end{array}$ \\
\hline ToptierEstrangeiro & - & Menor taxa de sucesso devido a um fator cultural & $\begin{array}{l}\text { Hunter e Jagtiani } \\
\text { (2003) e Golubov et } \\
\text { al. (2012) }\end{array}$ \\
\hline LnValor & - & $\begin{array}{l}\text { Devido a uma maior complexidade, relevância e } \\
\text { exposição, espera-se uma menor taxa de sucesso. }\end{array}$ & $\begin{array}{l}\text { Servaes e Zenner } \\
\text { (1996), Golubov } \text { et } \\
\text { al. (2012) }\end{array}$ \\
\hline CapitalEstrangeiro & - & $\begin{array}{l}\text { Devido a barreiras culturais, espera-se uma menor } \\
\text { taxa de sucesso. }\end{array}$ & Erel et al., (2012) \\
\hline Setor & + & $\begin{array}{l}\text { Espera-se que companhias adquirindo emum } \\
\text { mesmo setor leve a uma maior taxa de sucesso } \\
\text { devido a uma menor assimetria de informação. }\end{array}$ & $\begin{array}{l}\text { Servaes e Zenner } \\
\text { (1996), Golubov et } \\
\text { al. (2012) }\end{array}$ \\
\hline LnExpGeral & + & $\begin{array}{l}\text { Espera-se que uma maior experiência em negócios } \\
\text { aumente a taxa de sucesso. }\end{array}$ & $\begin{array}{l}\text { Servaes e Zenner } \\
\text { (1996), Golubov et } \\
\text { al. (2012) }\end{array}$ \\
\hline LnExpSemBanco & - & $\begin{array}{l}\text { Espera-se que uma maior experiência em negócios } \\
\text { sem o acompanhamento de um advisor aumente a } \\
\text { taxa de sucesso. }\end{array}$ & $\begin{array}{l}\text { Servaes e Zenner } \\
\text { (1996), Golubov et } \\
\text { al. (2012) }\end{array}$ \\
\hline AllStock & - & $\begin{array}{l}\text { Negócios pagos com ações têm uma maior } \\
\text { complexidade devido à necessidade de avaliação e até } \\
\text { emissão de novas ações, assim, espera-se que negócios } \\
\text { pagos dessa forma tenham uma menor taxa de sucesso. }\end{array}$ & $\begin{array}{l}\text { Servaes e Zenner } \\
\text { (1996), Golubov et } \\
\text { al. (2012) }\end{array}$ \\
\hline AllCash & + & $\begin{array}{l}\text { Negócios pagos com caixa têm uma menor } \\
\text { complexidade, assim, espera-se uma maior taxa de } \\
\text { sucesso. }\end{array}$ & $\begin{array}{l}\text { Servaes e Zenner } \\
\text { (1996), Golubov et } \\
\text { al. (2012) }\end{array}$ \\
\hline LnAt & + & $\begin{array}{l}\text { Quão maior for o alvo, maior a complexidade e } \\
\text { exposição do negócio, dessa forma, espera-se que } \\
\text { quanto maior, menor seja a taxa de sucesso, até por } \\
\text { questões regulatórias. }\end{array}$ & $\begin{array}{l}\text { Servaes e Zenner } \\
\text { (1996), Golubov et } \\
\text { al. (2012) }\end{array}$ \\
\hline
\end{tabular}


As Tabelas 6 e 7 demonstram as estimações de modelos logits com a variável dependente: o fato de o negócio ter sido completado ou não. Segundo Rau (2000) advisors são movidos por um sentimento de empire building, assim, tem incentivos para aumentar a sua fatia de mercado e sua reputação ajudando a completar o maior número de negócios possíveis. Hunter e Jagtiani (2003) argumentam que a economia de escala e a economia de especialização levam a uma porcentagem maior de sucesso nos negócios auxiliados por advisors. Foram estimadas as equações expostas na Tabela 6, para advisors de forma geral, e na Tabela 7 para os considerados toptiers.

Tabela 6

Taxa de Sucesso e Participação de Advisor

\begin{tabular}{|c|c|c|c|c|c|c|}
\hline & (1) & (2) & (3) & (4) & (5) & (6) \\
\hline Variáveis & Completo & Completo & Completo & Completo & Completo & Completo \\
\hline Amostra & Agregado & Abertas & Fechadas & Agregado & Abertas & Fechadas \\
\hline Advisor & $\begin{array}{l}0.165 * * * \\
(0.032)\end{array}$ & $\begin{array}{l}0.162 * * * \\
(0.052)\end{array}$ & $\begin{array}{l}0.113 * * * \\
(0.033)\end{array}$ & $\begin{array}{l}0.095^{* *} \\
(0.038)\end{array}$ & $\begin{array}{l}0.116^{* * * *} \\
(0.043)\end{array}$ & $\begin{array}{l}-0.187 \\
(0.120)\end{array}$ \\
\hline LnValor & $\begin{array}{l}-0.004 \\
(0.005)\end{array}$ & $\begin{array}{l}0.020^{*} \\
(0.011)\end{array}$ & $\begin{array}{l}-0.008^{*} \\
(0.004)\end{array}$ & $\begin{array}{l}0.010 \\
(0.009)\end{array}$ & $\begin{array}{l}0.013 \\
(0.010)\end{array}$ & $\begin{array}{l}0.034 \\
(0.027)\end{array}$ \\
\hline CapitalEstrangeiro & $\begin{array}{l}-0.032 \\
(0.028)\end{array}$ & $\begin{array}{l}-0.321 * * * \\
(0.081)\end{array}$ & $\begin{array}{l}0.007 \\
(0.021)\end{array}$ & $\begin{array}{l}-0.221 * * * \\
(0.055)\end{array}$ & $\begin{array}{l}-0.292 * * * \\
(0.064)\end{array}$ & $\begin{array}{l}-0.058 \\
(0.080)\end{array}$ \\
\hline Setor & $\begin{array}{l}-0.041 * * \\
(0.021)\end{array}$ & $\begin{array}{l}-0.054 \\
(0.039)\end{array}$ & $\begin{array}{l}-0.019 \\
(0.020)\end{array}$ & $\begin{array}{l}-0.042 \\
(0.027)\end{array}$ & $\begin{array}{l}-0.050^{*} \\
(0.030)\end{array}$ & $\begin{array}{l}-0.035 \\
(0.046)\end{array}$ \\
\hline LnExpGeral & $\begin{array}{l}-0.091 * * * \\
(0.026)\end{array}$ & $\begin{array}{l}-0.150 * * * \\
(0.043)\end{array}$ & $\begin{array}{l}-0.055^{*} \\
(0.033)\end{array}$ & $\begin{array}{l}-0.199 * * * \\
(0.039)\end{array}$ & $\begin{array}{l}-0.223 * * * \\
(0.043)\end{array}$ & $\begin{array}{l}0.138 \\
(0.143)\end{array}$ \\
\hline LnExpSemBanco & $\begin{array}{l}0.036 \\
(0.027)\end{array}$ & $\begin{array}{l}-0.086^{*} \\
(0.045)\end{array}$ & $\begin{array}{l}0.046 \\
(0.034)\end{array}$ & $\begin{array}{l}-0.026 \\
(0.039)\end{array}$ & $\begin{array}{l}-0.011 \\
(0.042)\end{array}$ & $\begin{array}{l}-0.240 \\
(0.172)\end{array}$ \\
\hline AllStock & $\begin{array}{l}-0.088^{*} \\
(0.049)\end{array}$ & $\begin{array}{l}-0.176^{* *} \\
(0.079)\end{array}$ & $\begin{array}{l}-0.036 \\
(0.076)\end{array}$ & $\begin{array}{l}-0.102 * \\
(0.057)\end{array}$ & $\begin{array}{l}-0.093 \\
(0.063)\end{array}$ & \\
\hline AllCash & $\begin{array}{l}-0.005 \\
(0.021)\end{array}$ & $\begin{array}{l}-0.064 \\
(0.040)\end{array}$ & $\begin{array}{l}0.027 \\
(0.019)\end{array}$ & $\begin{array}{l}-0.015 \\
(0.028)\end{array}$ & $\begin{array}{l}-0.042 \\
(0.032)\end{array}$ & $\begin{array}{l}0.070 \\
(0.070)\end{array}$ \\
\hline LnAt & & & & $\begin{array}{l}0.049 * * * \\
(0.012)\end{array}$ & $\begin{array}{l}0.054 * * * \\
(0.014)\end{array}$ & $\begin{array}{l}0.003 \\
(0.028)\end{array}$ \\
\hline R MacFadden & 0.249 & 0.3449 & 0.1726 & 0.2467 & 0.2587 & 0.4895 \\
\hline Likelihood & -1234.4 & -552.9 & -586.9 & -462.5 & -407.9 & -24.0 \\
\hline Acerto & $80.45 \%$ & $80.59 \%$ & $84.00 \%$ & $80.85 \%$ & $79.57 \%$ & $93.55 \%$ \\
\hline Roc & 0.8112 & 0.8686 & 0.7805 & 0.8216 & 0.8269 & 0.9182 \\
\hline Observations & 2,782 & 1,257 & 1,519 & 1,060 & 925 & 93 \\
\hline Indústria $\mathrm{FE}$ & Sim & Sim & Sim & Sim & Sim & Sim \\
\hline Ano FE & Sim & Sim & Sim & Sim & Sim & Sim \\
\hline
\end{tabular}

Nota. Entre parênteses está disposto o erro padrão robusto a heterocedasticidade, e foi estimada a seguinte regressão logística: Completo $=\alpha+\beta_{1}$ Acquirerbank $+\beta_{2}$ LnValor $+\beta_{3}$ Capital Estrangeiro $+\beta_{4}$ Setor $+\beta_{5}$ LnExpGeral + $\beta_{6}$ LnExpSemBanco $+\beta_{7}$ AllStock $+\beta_{8}$ Allcash $+\beta_{9}$ LnAt Todas as equações foram estimadas com efeitos fixos de tempo para controlar os fatores macroeconômicos e efeitos fixos de indústria para controlar as heterogeneidades constantes no tempo referente a cada grupo. Os coeficientes correspondem ao efeito marginal at means na probabilidade. Fonte: Elaborado pelos autores a partir da base de dados da Thomson Deal Scanner [Annual Data]. (1994-2016). Available: Thomson Reuters SDC [Apr/2017].

RAC, Rio de Janeiro, v. 22, n. 6, art. 3, pp. 859-884, novembro/dezembro, 2018, http://rac.anpad.org.br 
Tabela 7

Taxa de Sucesso e Advisor Toptier

\begin{tabular}{|c|c|c|c|c|c|}
\hline & (1) & (2) & (3) & (4) & (5) \\
\hline \multirow[t]{2}{*}{ VARIÁVEIS } & Completo & Completo & Completo & Completo & Completo \\
\hline & Agregado & Abertas & Fechadas & Agregado & Abertas \\
\hline \multirow[t]{2}{*}{ Toptier } & $0.150 * * *$ & $0.160 * * *$ & $0.111 * * *$ & $0.106 * * *$ & $0.115^{* *}$ \\
\hline & $(0.032)$ & $(0.055)$ & $(0.036)$ & $(0.040)$ & $(0.045)$ \\
\hline \multirow[t]{2}{*}{ LnValor } & -0.002 & $0.020^{*}$ & -0.007 & 0.011 & 0.014 \\
\hline & $(0.005)$ & $(0.011)$ & $(0.004)$ & $(0.008)$ & $(0.010)$ \\
\hline \multirow[t]{2}{*}{ CapitalEstrangeiro } & -0.034 & $-0.325 * * *$ & 0.006 & $-0.222 * * *$ & $-0.294 * * *$ \\
\hline & $(0.027)$ & $(0.080)$ & $(0.021)$ & $(0.054)$ & $(0.062)$ \\
\hline \multirow[t]{2}{*}{ Setor } & $-0.041 * *$ & -0.052 & -0.020 & -0.042 & -0.049 \\
\hline & $(0.021)$ & $(0.039)$ & $(0.021)$ & $(0.027)$ & $(0.030)$ \\
\hline \multirow[t]{2}{*}{ LnExpGeral } & $-0.064 * * *$ & $-0.128 * * *$ & -0.037 & $-0.195 * * *$ & $-0.212 * * *$ \\
\hline & $(0.024)$ & $(0.042)$ & $(0.032)$ & $(0.038)$ & $(0.042)$ \\
\hline \multirow[t]{2}{*}{ LnExpSemBanco } & 0.008 & $-0.112 * * *$ & 0.028 & -0.032 & -0.024 \\
\hline & $(0.025)$ & $(0.042)$ & $(0.034)$ & $(0.037)$ & $(0.041)$ \\
\hline \multirow[t]{2}{*}{ AllStock } & $-0.082 *$ & $-0.177 * *$ & -0.024 & $-0.105^{*}$ & -0.095 \\
\hline & $(0.048)$ & $(0.078)$ & $(0.073)$ & $(0.057)$ & $(0.063)$ \\
\hline \multirow[t]{2}{*}{ AllCash } & -0.005 & -0.063 & 0.027 & -0.014 & -0.041 \\
\hline & $(0.021)$ & $(0.040)$ & $(0.019)$ & $(0.028)$ & $(0.032)$ \\
\hline \multirow[t]{2}{*}{ LnAt } & & & & $0.049 * * *$ & $0.054 * * *$ \\
\hline & & & & $(0.011)$ & $(0.014)$ \\
\hline R MacFadden & 0.2451 & 0.3447 & 0.1713 & 0.2481 & 0.2586 \\
\hline Likelihood & -1237.3 & -533.0 & -587.7 & -461.6 & -408.0 \\
\hline Acerto & $80,45 \%$ & $80.75 \%$ & $83.87 \%$ & $80.94 \%$ & $79.89 \%$ \\
\hline Roc & 0.8100 & 0.8694 & 0.7798 & 0.8208 & 0.8275 \\
\hline Observations & 2,782 & 1,257 & 1,519 & 1,060 & 925 \\
\hline Indústria FE & Sim & Sim & Sim & Sim & Sim \\
\hline Ano FE & Sim & Sim & Sim & Sim & Sim \\
\hline
\end{tabular}

Nota. Entre parênteses está disposto o erro padrão robusto a heterocedasticidade, e foi estimada a seguinte regressão logística: $\quad$ Completo $=\alpha+\beta_{1}$ Toptier $+\beta_{2}$ LnValor $+\beta_{3}$ Capital Estrangeiro $+\beta_{4}$ Setor $+\beta_{5}$ LnExpGeral + $\beta_{6}$ LnExpSemBanco $+\beta_{7}$ AllStock $+\beta_{8}$ Allcash $+\beta_{9}$ LnAt Todas as equações foram estimadas com efeitos fixos de tempo para controlar os fatores macroeconômicos e efeitos fixos de indústria para controlar as heterogeneidades constantes no tempo referente a cada grupo. Os coeficientes correspondem ao efeito marginal at means na probabilidade. Fonte: Elaborado pelos autores a partir da base de dados da Thomson Deal Scanner [Annual Data]. (1994-2016). Available: Thomson Reuters SDC [Apr/2017].

Na primeira equação, Advisor é significante a $1 \%$ e positivo, com todas as outras variáveis na média, a sua presença aumenta a probabilidade de sucesso do negócio em $16 \%$. Para a equação (2), somente com companhias abertas, apresentou o mesmo efeito. Já para as companhias fechadas, equação 3, Advisor é significante a 1\%, porém, com um efeito econômico menor, um aumento de $11 \%$ 
na probabilidade de sucesso. Essa diferença de efeito entre as amostras de abertas e fechadas pode ser um indicativo de maior esforço devido a maior exposição dos negócios realizados por firmas de capital aberto, como demonstrado por Rhee e Valdez (2009), falha em situações de grande exposição levam a um maior dano reputacional. Ao adicionar a variável LnAt, para controlar pelo tamanho do adquirente, a variável mantém significância, porém com efeito econômico reduzido para $9 \%$ no agregado e $11 \%$ para a amostra de companhias de capital aberto. O resultado obtido na equação 6 pode ser devido ao tamanho da amostra.

Assim, há indícios do papel ativo do advisor na conclusão dos negócios, sejam os advisors movidos por Empire Building como argumentado por Rau (2000), ou pela economia de escala e especialização, como descrito por Hunter e Jagtiani (2003). Quanto aos controles, o porte da transação (proxy para complexidade, relevância e exposição) não se mostrou significante em relação à taxa de sucesso. Enquanto CapitalEstrangeiro mostrou-se inversamente relacionado à taxa de sucesso quando a adquirente é companhia aberta, ou seja, companhias abertas com controladores estrangeiros apresentam uma probabilidade $32 \%$ menor de concluírem os negócios anunciados. Esse efeito permanece mesmo quando controlado o tamanho da adquirente, inclusive tornando-se significante para o agregado. Dessa forma, a análise sugere que a diferença cultural impacta negativamente no sucesso das F\&A de maior exposição.

Golubov et al. (2012) levantam a hipótese de que alguns advisors - especialmente os considerados toptiers - podem ser contratados somente para finalizar o processo de F\&A. Assim, foi testado o modelo 2, presente na Tabela 7, com os advisors considerados toptiers.

$\mathrm{Na}$ amostra agregada, a presença de um toptier aumenta em 15\% a probabilidade do negócio ser completado em relação ao restante, esse valor se mantém quando considerado apenas as companhias abertas e diminui para as companhias fechadas. Ao controlar pelo tamanho da adquirente, a significância permanece, mas o efeito econômico diminui para cerca de $10 \%$ no aumento da probabilidade de sucesso.

A partir desses resultados, é possível inferir que a participação de um advisor está associada a um aumento na probabilidade de sucesso do negócio, e a presença de um toptier no empreendimento aumenta essa probabilidade em relação aos advisors secondtier e também em relação aos negócios realizados In-house. Esse resultado está em linha com os achados de Hunter e Jagtiani (2003) e Golubov et al. (2012), ambos para o mercado americano.

\section{Determinantes da participação}

Para identificar os determinantes da participação de um advisor na negociação, foi estimado o modelo 3. A Tabela 8 resume a fundamentação teórica e o sinal esperado das variáveis incluídas no modelo 3, de determinantes da participação do Advisor. 
Tabela 8

\section{Resumo Teórico Acerca da Participação de Advisors}

\begin{tabular}{|c|c|c|c|}
\hline Variável & Sinal esperado & Fundamentação teórica & Referencias \\
\hline LnValor & - & $\begin{array}{l}\text { Devido a uma maior complexidade, relevância e } \\
\text { exposição, espera-se participação de advisors nesse tipo } \\
\text { de transação. }\end{array}$ & $\begin{array}{l}\text { Servaes e Zenner } \\
\text { (1996), Golubov } \\
\text { et al. (2012) }\end{array}$ \\
\hline CapitalEstrangeiro & - & $\begin{array}{l}\text { Devido a barreiras culturais, espera-se a participação de } \\
\text { advisors. }\end{array}$ & $\begin{array}{l}\text { Erel et al., } \\
(2012)\end{array}$ \\
\hline Setor & + & $\begin{array}{l}\text { Espera-se que companhias adquirindo em um mesmo } \\
\text { setor sejam menos propensas a contratar um advisor } \\
\text { devido a menor assimetria informacional. }\end{array}$ & $\begin{array}{l}\text { Servaes e Zenner } \\
\text { (1996), Golubov } \\
\text { et al. (2012) }\end{array}$ \\
\hline LnExpGeral & + & $\begin{array}{l}\text { Espera-se que uma maior experiencia em negócios } \\
\text { diminua a probabilidade de participação de um advisor }\end{array}$ & $\begin{array}{l}\text { Servaes e Zenner } \\
\text { (1996), Golubov } \\
\text { et al. (2012) }\end{array}$ \\
\hline LnExpSemBanco & - & $\begin{array}{l}\text { Espera-se que uma maior experiencia em negócios sem o } \\
\text { acompanhamento de um advisor diminua a } \\
\text { probabilidade de contratação de um. }\end{array}$ & $\begin{array}{l}\text { Servaes e Zenner } \\
\text { (1996), Golubov } \\
\text { et al. (2012) }\end{array}$ \\
\hline AllStock & - & $\begin{array}{l}\text { Negócios pagos com ações tem uma maior } \\
\text { complexidade devido à necessidade de avaliação e até } \\
\text { emissão de novas ações, assim, espera-se que negócios } \\
\text { pagos dessa forma tenham uma maior participação de } \\
\text { advisors devido a sua complexidade. }\end{array}$ & $\begin{array}{l}\text { Servaes e Zenner } \\
\text { (1996), Golubov } \\
\text { et al. (2012) }\end{array}$ \\
\hline AllCash & + & $\begin{array}{l}\text { Negócios pagos com caixa tem uma menor } \\
\text { complexidade, assim, espera-se uma menor participação } \\
\text { de advisors nessas operações. }\end{array}$ & $\begin{array}{l}\text { Servaes e Zenner } \\
\text { (1996), Golubov } \\
\text { et al. (2012) }\end{array}$ \\
\hline LnAt & + & $\begin{array}{l}\text { Quão maior for o alvo, maior a complexidade e } \\
\text { exposição do negócoio, dessa forma, espera-se uma } \\
\text { maior participação de advisors nessas operações. }\end{array}$ & $\begin{array}{l}\text { Servaes e Zenner } \\
\text { (1996), Golubov } \\
\text { et al. (2012) }\end{array}$ \\
\hline
\end{tabular}

Em todas as equações, o valor mostrou-se significante a 1\%. Ao considerar a amostra agregada, um aumento de $1 \%$ no valor, aumenta a probabilidade de participação de um advisor em $4 \%$. Para as abertas, esse aumento é de aproximadamente $16 \%$ e para as fechadas de apenas $1 \%$. Ao controlar pelo tamanho da companhia adquirente, essa probabilidade aumenta em 17\% para o agregado e $19 \%$ para as abertas. Esse resultado está em linha com o achado de Servaes e Zenner (1996), Golubov et al. (2012) que atribuem a participação do advisor ao porte da negociação, de modo a diminuir os custos da transação e aumentar o ganho com a economia de especialização. A Tabela 9 exibe os resultados estimados por meio do modelo 3 . 
Tabela 9

Determinantes da Participação

\begin{tabular}{|c|c|c|c|c|c|}
\hline & (1) & (2) & (3) & (4) & (5) \\
\hline & Advisor & Advisor & Advisor & Advisor & Advisor \\
\hline Amostra: & Agregado & Abertas & Fechadas & Agregado & Abertas \\
\hline \multirow[t]{2}{*}{ LnValor } & $0.049 * * *$ & $0.164 * * *$ & $0.011 * * *$ & $0.171^{* * *}$ & $0.195 * * *$ \\
\hline & $(0.005)$ & $(0.018)$ & $(0.003)$ & (0.019) & $(0.023)$ \\
\hline \multirow[t]{2}{*}{ CapitalEstrangeiro } & $-0.040 *$ & -0.185 & -0.006 & -0.296 & -0.196 \\
\hline & $(0.024)$ & $(0.175)$ & $(0.009)$ & $(0.183)$ & $(0.197)$ \\
\hline \multirow[t]{2}{*}{ Setor } & -0.006 & 0.009 & -0.011 & 0.015 & -0.002 \\
\hline & $(0.015)$ & $(0.055)$ & $(0.008)$ & $(0.058)$ & $(0.062)$ \\
\hline \multirow[t]{2}{*}{ LnExpGeral } & $0.399 * * *$ & $0.917 * * *$ & $0.126^{* * *}$ & $1.113 * * *$ & $1.058 * * *$ \\
\hline & $(0.048)$ & $(0.145)$ & $(0.036)$ & $(0.175)$ & $(0.183)$ \\
\hline \multirow[t]{2}{*}{ LnExpSemBanco } & $-0.374 * * *$ & $-0.895 * * *$ & $-0.119 * * *$ & $-1.045 * * *$ & $-1.002 * * *$ \\
\hline & $(0.047)$ & $(0.151)$ & $(0.034)$ & $(0.175)$ & $(0.185)$ \\
\hline \multirow[t]{2}{*}{ AllStock } & $0.086 * *$ & $0.279 * * *$ & -0.006 & $0.250 * *$ & $0.254 * *$ \\
\hline & $(0.034)$ & $(0.104)$ & $(0.013)$ & $(0.115)$ & $(0.121)$ \\
\hline \multirow[t]{2}{*}{ AllCash } & -0.003 & 0.056 & -0.004 & 0.039 & 0.070 \\
\hline & $(0.014)$ & $(0.059)$ & $(0.005)$ & $(0.064)$ & $(0.067)$ \\
\hline \multirow[t]{2}{*}{ LnAt } & & & & $-0.040 * *$ & $-0.040 * *$ \\
\hline & & & & (0.019) & $(0.018)$ \\
\hline R MacFadden & 0.5924 & 0.5633 & 0.6260 & 0.5486 & 0.5521 \\
\hline Likelihood & -446.0 & -219.7 & -191.9 & -236.4 & -201.4 \\
\hline Acerto & $90.49 \%$ & $87.42 \%$ & $93.36 \%$ & $87.72 \%$ & $86.96 \%$ \\
\hline Roc & 0.9604 & 0.9484 & 0.9680 & 0.9454 & 0.9449 \\
\hline Observations & 1,997 & 755 & 1,204 & 782 & 667 \\
\hline Indústria FE & Sim & Sim & Sim & Sim & Sim \\
\hline Ano FE & Sim & Sim & Sim & Sim & Sim \\
\hline
\end{tabular}

Nota. Entre parênteses está disposto o erro padrão robusto a heterocedasticidade, e foi estimada a seguinte regressão logística: $\quad$ AcquirerBank $=\alpha+\beta_{1}$ LnValor $+\beta_{2}$ CapitalEstrangeiro $+\beta_{3}$ Setor $+\beta_{4}$ LnExpGeral + $\beta_{5}$ LnExpSemBanco $+\beta_{6}$ AllStock $+\beta_{7}$ Allcash $+\beta_{9}$ LnAt Todas as equações foram estimadas com efeitos fixos de tempo para controlar os fatores macroeconômicos e efeitos fixos de indústria para controlar as heterogeneidades constantes no tempo referente a cada grupo. Os coeficientes correspondem ao efeito marginal at means na probabilidade. Fonte: Elaborado pelos autores a partir da base de dados da Thomson Deal Scanner [Annual Data]. (1994-2016). Available: Thomson Reuters SDC [Apr/2017].

A hipótese de assimetria informacional elaborada por Servaes e Zenner (1996) não foi confirmada tendo em vista que a adquirente e adquirida fazerem parte do mesmo setor econômico não se mostrou significante estatisticamente. 
O logaritmo natural da experiência anterior da companhia adquirente foi significante a $1 \%$ em todas as equações, indicando que um aumento de $1 \%$ na experiência, está associado a um aumento de probabilidade da participação de um advisor na negociação em 39\% para a o agregado, $91 \%$ para as abertas, $12 \%$ para as fechadas. Ao controlar pelo tamanho da companhia adquirente - da mesma forma que aconteceu com o valor - ocorre um aumento, para $111 \%$ na amostra agregada e $105 \%$ nas abertas. Esse resultado não está em linha com estudos anteriores como Golubov et al. (2012) e Servaes e Zenner (1996), os quais, argumentam que quanto maior a experiência em operações de F\&A, maior a expertise da empresa e maior probabilidade de utilizar o serviço In-house. Uma possível explicação para o resultado contrário, pode ser o complicado ambiente de negócios brasileiro, onde o ganho com a expertise do advisor possivelmente é maior do que o custo pago pela sua participação, inclusive na ausência da propriedade dispersa e assim, na ausência da necessidade de certificação.

A variável LnExpSemBanco, o logaritmo natural da experiência da companhia adquirente em negócios sem a participação de advisor, mostrou-se significante em todos os modelos também a 1\%, porém, como esperado, um aumento na experiência sem advisor, diminui a probabilidade de participação do advisor em $37 \%$ na amostra agregada, $89 \%$ para as abertas e $11 \%$ para as fechadas. Ao controlar por tamanho, esse valor sobe para $104 \%$ no agregado e $100 \%$ para as abertas. Esse resultado está em linha com Golubov et al. (2012), o qual argumenta que um aumento de experiência se deve/leva à criação de departamentos de F\&A dentro das firmas, e assim, exclui-se a necessidade de contratação fora.

Outra variável significante para a participação de advisor foi a forma de pagamento (proxy para a complexidade do negócio). Caso a forma de pagamento seja somente em ações, a probabilidade de participação de um advisor aumenta em 8\% para a amostra agregada, 27\% para as abertas. Para as companhias fechadas, essa variável não demonstra significância estatística. Ao controlar por tamanho, esse valor aumenta para $25 \%$ no agregado como também para a amostra de companhias abertas, demonstrando assim a possível importância de uma correta avaliação feita por um advisor.

A Tabela 10 tem como variável dependente a participação de um toptier. O valor pago foi significante e positivo para todos os modelos, nas equações 4 e 5 , um aumento de $1 \%$ no valor, aumenta a probabilidade de participação de um em $12 \%$ para a amostra total, para as abertas o aumento é de $13 \%$. Diferente da Tabela 9, o aumento de $1 \%$ na experiência geral, aumenta a probabilidade de participação em aproximadamente $15 \%$ para o agregado, $33 \%$ quando considerada só abertas e esse valor decai para $9 \%$ em relação as fechadas.

Tabela 10

Determinantes de Advisor Toptier

\begin{tabular}{lccccc}
\hline \multirow{2}{*}{ Variáveis } & $(1)$ & $(2)$ & $(3)$ & $(4)$ & $(5)$ \\
Amostra & Toptier & Toptier & Toptier & Toptier & Toptier \\
\hline LnValor & Agregado & Abertas & Fechadas & Agregado & Abertas \\
& $0.032^{* * *}$ & $0.108^{* * *}$ & $0.009^{* * *}$ & $0.121^{* * *}$ & $0.136^{* * *}$ \\
CapitalEstrangeiro & $(0.004)$ & $(0.013)$ & $(0.002)$ & $(0.016)$ & $(0.018)$ \\
& $-0.053^{* * *}$ & -0.100 & $-0.020^{* *}$ & -0.159 & -0.116 \\
Setor & $(0.018)$ & $(0.110)$ & $(0.010)$ & $(0.124)$ & $(0.139)$ \\
& 0.014 & 0.045 & -0.001 & 0.038 & 0.034 \\
LnExpGeral & $(0.009)$ & $(0.033)$ & $(0.007)$ & $(0.040)$ & $(0.042)$ \\
& $0.149 * * *$ & $0.337^{* * *}$ & $0.090^{* * *}$ & $0.491 * * *$ & $0.430^{* * *}$ \\
& $(0.019)$ & $(0.049)$ & $(0.022)$ & $(0.070)$ & $(0.069)$ \\
\hline
\end{tabular}


Tabela 10 (continuação)

(1)

(2)

(3)

(4)

(5)

\begin{tabular}{|c|c|c|c|c|c|}
\hline Variáveis & Toptier & Toptier & Toptier & Toptier & Toptier \\
\hline Amostra & Agregado & Abertas & Fechadas & Agregado & Abertas \\
\hline \multirow[t]{2}{*}{ LnExpSemBanco } & $-0.133 * * *$ & $-0.280 * * *$ & $-0.084 * * *$ & $-0.415^{* * *}$ & $-0.355 * * *$ \\
\hline & $(0.018)$ & $(0.046)$ & $(0.021)$ & $(0.065)$ & $(0.063)$ \\
\hline \multirow[t]{2}{*}{ AllStock } & $0.047 * *$ & $0.108^{*}$ & 0.006 & $0.131^{*}$ & $0.135^{*}$ \\
\hline & $(0.020)$ & $(0.057)$ & $(0.015)$ & $(0.076)$ & $(0.073)$ \\
\hline \multirow[t]{2}{*}{ AllCash } & -0.006 & 0.009 & -0.004 & 0.007 & 0.026 \\
\hline & $(0.009)$ & $(0.035)$ & $(0.006)$ & $(0.043)$ & $(0.045)$ \\
\hline \multirow[t]{2}{*}{ LnAt } & & & & $-0.021 *$ & -0.019 \\
\hline & & & & $(0.012)$ & $(0.012)$ \\
\hline R MacFadden & 0.4921 & 0.4835 & 0.5192 & 0.4745 & 0.4831 \\
\hline Likelihood & -468.3 & -233.3 & -195.8 & -252.8 & -213.1 \\
\hline Acerto & $89.02 \%$ & $85.62 \%$ & $92.18 \%$ & $86.01 \%$ & $85.45 \%$ \\
\hline Roc & 0.9372 & 0.9283 & 0.9528 & 0.9247 & 0.9278 \\
\hline Observations & 1,949 & 737 & 1,164 & 765 & 653 \\
\hline Indústria FE & Sim & Sim & Sim & Sim & Sim \\
\hline Ano FE & Sim & Sim & Sim & Sim & Sim \\
\hline
\end{tabular}

Nota. Entre parênteses está disposto o erro padrão robusto a heterocedasticidade, e foi estimada a seguinte regressão logística: Toptier $=\alpha+\beta_{1}$ LnValor $+\beta_{2}$ Capital Estrangeiro $+\beta_{3}$ Setor $+\beta_{4}$ LnExpGeral $+\beta_{5}$ LnExpSemBanco + $\beta_{6}$ AllStock $+\beta_{7}$ Allcash $+\beta_{9}$ LnAt Todas as equações foram estimadas com efeitos fixos de tempo para controlar os fatores macroeconômicos e efeitos fixos de indústria para controlar as heterogeneidades constantes no tempo referente a cada grupo. Os coeficientes correspondem ao efeito marginal at means na probabilidade. Fonte: Elaborado pelos autores a partir da base de dados da Thomson Deal Scanner [Annual Data]. (1994-2016). Available: Thomson Reuters SDC [Apr/2017].

Já quando controlado pelo tamanho, esse valor cai aproximadamente pela metade em relação à Tabela 9, com um aumento de $49 \%$ na probabilidade para o agregado e $43 \%$ para as abertas. Outra diferença encontrada foi a perda de significância da variável AllStock, indicando que a forma de pagamento não influencia na sua participação. Isto posto, a escolha por um toptier não parece estar ligada à complexidade do negócio e sim com o porte, ou seja, com a exposição e relevância.

Ao dividir os toptiers em brasileiros, Tabela 11, o valor da transação continuou significante estatisticamente, porém com pouco significado econômico, pois em todos os modelos estimados, o aumento na probabilidade de participação foi menor do que $2 \%$, indicando que o porte do negócio não tem relação econômica com a escolha de um advisor brasileiro. LnExpGeral e LnExpSemBanco continuaram significantes como nos modelos anteriores. É importante notar que, na amostra agregada, o controlador da empresa ser estrangeiro diminui a probabilidade de contratação de um toptier nacional em $7 \%$ e $3 \%$ na equação 3 . A variável não pode ser estimada nas equações 2,4 e 5 por não haver variação. 
Tabela 11

Determinantes de Advisor Toptier Brasileiro

\begin{tabular}{|c|c|c|c|c|c|}
\hline & (1) & (2) & (3) & (4) & (5) \\
\hline Variáveis & Toptierbr & Toptierbr & Toptierbr & Toptierbr & Toptierbr \\
\hline Amostra & Agregado & Abertas & Fechadas & Agregado & Abertas \\
\hline \multirow[t]{2}{*}{ LnValor } & $0.006^{* * *}$ & $0.009^{* *}$ & $0.005^{* * *}$ & $0.015^{* * *}$ & $0.009 *$ \\
\hline & $(0.002)$ & $(0.005)$ & $(0.002)$ & $(0.005)$ & $(0.005)$ \\
\hline \multirow[t]{2}{*}{ CapitalEstrangeiro } & $-0.071 * * *$ & & $-0.036^{* * *}$ & & \\
\hline & $(0.015)$ & & $(0.012)$ & & \\
\hline \multirow[t]{2}{*}{ Setor } & -0.001 & -0.005 & -0.005 & -0.012 & -0.002 \\
\hline & $(0.005)$ & $(0.017)$ & $(0.007)$ & $(0.016)$ & $(0.017)$ \\
\hline \multirow[t]{2}{*}{ LnExpGeral } & $0.034 * * *$ & $0.079 * * *$ & $0.035^{* * *}$ & $0.091 * * *$ & $0.083 * * *$ \\
\hline & (0.008) & $(0.020)$ & $(0.011)$ & $(0.021)$ & $(0.022)$ \\
\hline \multirow[t]{2}{*}{ LnExpSemBanco } & $-0.031 * * *$ & $-0.048 * * *$ & $-0.032 * * *$ & $-0.060 * * *$ & $-0.052 * * *$ \\
\hline & $(0.007)$ & $(0.018)$ & $(0.011)$ & $(0.020)$ & $(0.020)$ \\
\hline \multirow[t]{2}{*}{ AllStock } & $0.017^{*}$ & $0.061 * *$ & 0.016 & 0.042 & $0.066^{* *}$ \\
\hline & (0.009) & $(0.031)$ & $(0.016)$ & $(0.030)$ & $(0.032)$ \\
\hline \multirow[t]{2}{*}{ AllCash } & -0.004 & -0.012 & -0.002 & 0.005 & -0.011 \\
\hline & (0.005) & $(0.016)$ & $(0.004)$ & $(0.016)$ & $(0.016)$ \\
\hline \multirow[t]{2}{*}{ LnAt } & & & & $-0.010^{* *}$ & -0.005 \\
\hline & & & & (0.004) & $(0.004)$ \\
\hline R MacFadden & 0.3068 & 0.2991 & 0.4016 & 0.2847 & 0.3029 \\
\hline Likelihood & -296.2 & -134.6 & -126.8 & -167.3 & -130.6 \\
\hline Acerto & $92.65 \%$ & $91.06 \%$ & $93.77 \%$ & $89.29 \%$ & $90.68 \%$ \\
\hline Roc & 0.8877 & 0.8556 & 0.9262 & 0.8524 & 0.8548 \\
\hline Observations & 1,552 & 537 & 786 & 616 & 515 \\
\hline Indústria FE & Sim & Sim & Sim & Sim & Sim \\
\hline Ano FE & Sim & Sim & Sim & Sim & Sim \\
\hline
\end{tabular}

Nota. Entre parênteses está disposto o erro padrão robusto a heterocedasticidade, e foi estimada a seguinte regressão logística: $\quad$ ToptierBr $=\alpha+\beta_{1}$ LnValor $+\beta_{2}$ Capital Estrangeiro $+\beta_{3}$ Setor $+\beta_{4}$ LnExpGeral + $\beta_{5}$ LnExpSemBanco $+\beta_{6}$ AllStock $+\beta_{7}$ Allcash $+\beta_{9}$ LnAt Todas as equações foram estimadas com efeitos fixos de tempo para controlar os fatores macroeconômicos e efeitos fixos de indústria para controlar as heterogeneidades constantes no tempo referente a cada grupo. Os coeficientes correspondem ao efeito marginal at means na probabilidade. Fonte: Elaborado pelos autores a partir da base de dados da Thomson Deal Scanner [Annual Data]. (1994-2016). Available: Thomson Reuters SDC [Apr/2017]. 


\section{Considerações Finais}

O presente estudo teve como objetivo investigar o papel do advisor nas F\&A ocorridas no Brasil no período de janeiro de 1994 até junho de 2016 e os determinantes de sua participação. Quanto ao seu papel, verificou-se que os negócios em que ocorrem sua participação levam um maior tempo para serem concluídos. Isso sugere um papel ativo nos negócios, haja vista que um maior tempo significa uma maior quantidade de diligências na firma adquirida. Este resultado sugere que mesmo em um mercado onde não é necessário a certificação para o acionista, devido à alta concentração acionária, o advisor exerce um papel importante na transação.

Quanto a taxa de sucesso, a presença de um advisor também mostrou-se significante tanto estatisticamente quanto economicamente para todas as estimações e subamostras (companhias abertas, fechadas e amostra agregada), corroborando o papel ativo do advisor e sua eficiência em concluir o negócio. Todavia, ser toptier, de nacionalidade brasileira ou estrangeira não foi diferente estatisticamente dos outros.

Em relação a sua participação, num ambiente de propriedade concentrada e de negócios não hostis, ela está associada à complexidade do negócio e porte, já que o valor da transação (proxy para porte) foi significante tanto estatisticamente quanto economicamente em todos os modelos e subamostras, e também o pagamento com ações, proxy para complexidade, indicando participação do advisor quanto à avaliação da adquirida ou como um participante útil na possível emissão futura de ações, como moeda para o pagamento.

Todavia, no Brasil, de encontro aos estudos internacionais, a participação está associada com uma maior experiência dos adquirentes, indicando que quanto maior for o número de negócios realizados, maior a probabilidade de contratação de advisor. Uma possível explicação é o real valor adicionado por um advisor nas negociações - mesmo com a concentração acionária e ausência de aquisições hostis - percebido pela companhia com o aumento da experiência. E a hipótese da assimetria informacional, representada pela variável referente à aquisição ser em um mesmo setor não se mostrou significante.

Dessa forma, este artigo contribui para literatura nacional e internacional ao apresentar evidências do papel dos advisors e características das transações que são determinantes para sua participação em um mercado concentrado e em desenvolvimento.

Como limitação, não é possível verificar nem inferir causalidade a partir dos nossos dados e desenho de pesquisa, pois, para fazê-lo, seria necessário um evento que atribuísse aleatoriamente os diferentes advisors entre as transações, entretanto, isso dificilmente acontecerá na prática.

Como indicações para estudos futuros, pode ser estudada a relação entre a persistência de um advisor nos consecutivos processos de F\&A de uma mesma empresa e as determinantes para essa relação.

\section{Material Suplementar}

Todos os dados e materiais foram disponibilizados publicamente por meio da plataforma Mendeley e podem ser acessados em: ERMEL, MARCELO DANIEL ARAUJO (2018), "Data for: "Perfil da participação do Advisor nas Fusões e Aquisições no Brasil" Published at RAC ”, Mendeley Data, v1 http://dx.doi.org/10.17632/rfybj4xc6w.1 


\section{Contribuições}

$1^{\circ}$ autor: revisão de literatura, definição de pesquisa, coleta e análise de dados, redação e revisão do referido manuscrito.

$2^{\circ}$ autor: revisão de literatura, redação e revisão do referido manuscrito.

\section{Referências}

Allen, L., Jagtiani, J., Peristiani, S., \& Saunders, A. (2004). The role of bank advisors in mergers and acquisitions. Journal of Money, Credit, and Banking, 36(2), 197-224.

Bao, J., \& Edmans, A. (2011). Do investment banks matter for M\&A returns?. The Review of Financial Studies, 24(7), 2286-2315. https://doi.org/10.1093/rfs/hhr014

Benston, G. J., Smith, J. R., Clifford, W. (1976). A transactions cost approach to the theory of financial intermediation. The Journal of Finance, 31(2), 215-231. https://doi.org/10.1111/j.1540-6261.1976.tb01882.x

Bhattacharya, D., Hsu, S. C., Li, W. H., \& Liu, C. T. (in press). A combined firm's decision to hire the target's financial advisor after acquisition: Does "service excellence" pay off?. Finance Research Letters. https://doi.org/10.1016/j.frl.2018.08.004

Bi, X., \& Wang, D. (2018). Top-tier financial advisors, expropriation and Chinese mergers \& acquisitions. International Review of Financial Analysis, 57, 157-166. https://doi.org/10.1016/j.irfa.2018.03.002

Bowers, H. M., \& Miller, R. E. (1990). Choice of investment banker and shareholders' wealth of firms involved in acquisitions. Financial Management, 19(4), 34-44. https://doi.org/10.2307/3665608

Brito, G. A. S., Batistella, F. D., \& Famá, R. (2005). Fusões e aquisições no setor bancário: Avaliação empírica do efeito sobre o valor das ações. Revista de Administração da USP, 40(4).

Camargos, M. A. de., \& Vidal Barbosa, F. (2006). Eficiência informacional do mercado de capitais brasileiro pós-Plano Real: Um estudo de eventos dos anúncios de fusões e aquisições. Revista de Administração da USP, 41(1), 353-360.

Cornaggia, K. R., \& Rau, P. R. (2002). Do bidders hire top-tier investment banks to certify value?. [Working Paper]. Social Science Research Network, Rochester, NY. Recuperado de https://papers.ssrn.com/sol3/papers.cfm?abstract_id=298172

Derrien, F., \& Dessaint, O. (2018). The effects of investment bank rankings: Evidence from M\&A league tables. Review of Finance, 22(4), 1375-1411. https://doi.org/10.1093/rof/rfx056

Easterbrook, F. H. (1984). Two agency-cost explanations of dividends. The American Economic Review, 74(4), 650-659.

Erel, I., Liao, R. C., \& Weisbach, M. S. (2012). Determinants of cross-border mergers and acquisitions. The Journal of Finance, 67(3), 1045-1082. https://doi.org/10.1111/j.15406261.2012.01741.x

Ermel, M. D. A., \& Monte, P. A. do (2018). Shareholder control, firm performance and executive compensation: Evidence from Brazilian market. Brazilian Review of Finance, 16(3), 455-491. 
Forte, G., Iannotta, G., \& Navone, M. (2010). The banking relationship's role in the choice of the target's advisor in mergers and acquisitions. European Financial Management, 16(4), 686-701. https://doi.org/10.1111/j.1468-036X.2009.00481.x

Francis, B. B., Hasan, I., \& Sun, X. (2014). Does relationship matter? The choice of financial $\begin{array}{llll}\text { advisors. Journal of } & \text { Economics } 47 .\end{array}$ https://doi.org/10.1016/j.jeconbus.2013.12.002

Golubov, A., Petmezas, D., \& Travlos, N. G. (2012). When it pays to pay your investment banker: New evidence on the role of financial advisors in M\&As. The Journal of Finance, 67(1), 271311. https://doi.org/10.1111/j.1540-6261.2011.01712.x

Guo, J. M., Li, Y., Wang, C., \& Xing, X. (in press). The role of investment bankers in M\&As: New evidence on acquirers' financial conditions. Journal of Banking \& Finance.

Hunter, W. C., \& Jagtiani, J. (2003). An analysis of advisor choice, fees, and effort in mergers and acquisitions. Review of Financial Economics, 12(1), 65-81. https://doi.org/10.1016/S10583300(03)00007-7

Kale, J. R., Kini, O., \& Ryan, H. E. (2003). Financial advisors and shareholder wealth gains in corporate takeovers. Journal of Financial and Quantitative Analysis, 38(3), 475-501. https://doi.org/10.2307/4126728

Kisgen, D. J., \& Song, W. (2009). Are fairness opinions fair? The case of mergers and acquisitions. Journal of Financial Economics, 91(2), 179-207. https://doi.org/10.1016/j.jfineco.2008.03.001

Leal, R. P. C., Almeida, V. D. S., \& Bortolon, P. M. (2013). Brazilian scientific production in finance in the period 2000-2010. Revista de Administração de Empresas, 53(1), 46-55. http://doi.org/10.1590/S0034-75902013000100005

Leal, R. P. C., Silva, A. L. C. D., \& Valadares, S. M. (2002). Estrutura de controle das companhias brasileiras de capital aberto. Revista de Administração Contemporânea, 6(1), 7-18. Recuperado de http://www.scielo.br/pdf/rac/v6n1/v6n1a02.pdf. http://doi.org/10.1590/S141565552002000100002

Pasin, R., \& Martelanc. R. (2017). Fusões \& aquisições: Casos de fracasso e sucesso na destruição e geração de valor. São Paulo. Editora FIA.

Rau, P. R. (2000). Investment bank market share, contingent fee payments, and the performance of acquiring firms. Journal of Financial Economics, 56(2), 293-324. https://doi.org/10.1016/S0304-405X(00)00042-8

Rhee, M., \& Valdez, M. E. (2009). Contextual factors surrounding reputation damage with potential implications for reputation repair. Academy of Management Review, 34(1), 146-168.

Scholes, M., Benston, G. J., \& Smith, C. W. (1976). A transactions cost approach to the theory of financial intermediation. The Journal of Finance, 31(2), 215-231.https://doi.org/10.1111/j.15406261.1976.tb01882.x

Servaes, H., \& Zenner, M. (1996). The role of investment banks in acquisitions. The Review of Financial Studies, 9(3), 787-815. https://doi.org/10.1093/rfs/9.3.787

Song, W., Wei, J. D., \& Zhou, L. (2013). The value of "boutique" financial advisors in mergers and acquisitions. Journal of Corporate Finance, 20, 94-114. https://doi.org/10.1016/j.jcorpfin.2012.12.003

Steinberg, F., \& Silva, A. L. C. (2009). Governança corporativa e ganhos de fusões e aquisições no Brasil. Decisões de Investimentos, 7, 169-190. 
Thomas, H. A. (1995). Effects of firm owenership structure on hiring of M\&A advisors. Journal of Financial Services Research, 9(2), 159-175. https://doi.org/10.1007/BF01068076

Thomson Deal Scanner [Annual Data]. (1994-2016). Available: Thomson Reuters SDC [Apr/2017].

\section{Autores}

Marcelo Daniel Araújo Ermel

Av. 9 de Julho, 2029, 01313-902, Bela Vista, São Paulo, SP, Brasil.

E-mail: ermel.marcelo@gmail.com

Roy Martelanc

Av. Prof. Luciano Gualberto, 908, 05508-010, Butantã, São Paulo, SP, Brasil.

E-mail: rmartela@usp.br 